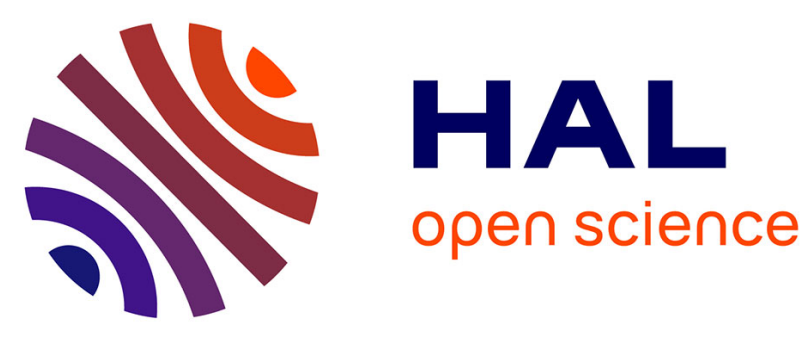

\title{
Effect of electric current on densification behavior of conductive ceramic powders consolidated by spark plasma sintering
}

Geuntak Lee, Eugene A. Olevsky, Charles Manière, Andrey Maximenko, Oleg Izhvanov, Christina Back, Joanna Mckittrick, Geuntak Leeabeugene, A Olevskyac, Charles Manièrea, et al.

\section{To cite this version:}

Geuntak Lee, Eugene A. Olevsky, Charles Manière, Andrey Maximenko, Oleg Izhvanov, et al.. Effect of electric current on densification behavior of conductive ceramic powders consolidated by spark plasma sintering. Acta Materialia, 2018, 144, pp.524-533. 10.1016/j.actamat.2017.11.010 . hal-02616820

\section{HAL Id: hal-02616820}

https://hal-normandie-univ.archives-ouvertes.fr/hal-02616820

Submitted on 30 Nov 2020

HAL is a multi-disciplinary open access archive for the deposit and dissemination of scientific research documents, whether they are published or not. The documents may come from teaching and research institutions in France or abroad, or from public or private research centers.
L'archive ouverte pluridisciplinaire HAL, est destinée au dépôt et à la diffusion de documents scientifiques de niveau recherche, publiés ou non, émanant des établissements d'enseignement et de recherche français ou étrangers, des laboratoires publics ou privés. 


\title{
Effect of electric current on densification behavior of conductive ceramic powders consolidated by spark plasma sintering
}

Geuntak LeeabEugene A.Olevskyac Charles Manièrea Andrey Maximenkoa Oleg Izhvanovd Christina Backd Joanna McKittrickb

\begin{abstract}
The densification mechanism of conductive powders is revealed by comparing the electric currentassisted spark plasma sintering (SPS) of ZrN powder with conventional hot pressing (HP) carried out with the same powder and under the same pressure and temperature. To determine the actual temperature inside ZrN powder, a sacrificial thermocouple is directly inserted into the powder during the SPS process. The spatial distribution of the electric current passing through the powder is calculated using the finite element modeling. The porosity-interparticle neck area geometrical relationship is applied to estimate the electric current density inside the powder volume subjected to SPS. For the first time, by taking into account the explicit influence of the electric current effect on the SPS densification mechanism, the constitutive equations describing the electric current-assisted hot pressing of powders are developed. The densification mechanism of $\mathrm{ZrN}$ is determined by the inverse regression of the new SPS constitutive equations and by utilizing the experimental results on $\mathrm{ZrN}$ powder consolidation with and without the participation of the electric current effect.
\end{abstract}

\section{Keywords}

Spark Plasma SinteringHot-pressingConstitutive equationSinteringZrN

\section{Introduction}

In comparison with conventional powder consolidation methods like hot pressing (HP), spark plasma sintering (SPS) can lower the sintering temperature and reduce sintering times, thus favoring the reduction of the grain size of compacted pellets and saving the energy spent. However, in the past, possible mechanisms responsible for these clear advantages of SPS have been discussed in a controversial way.

Early reports considered the effect of surface cleaning [1], [2]. The electric current may lead to the breakdown of insulating layers on the surface of powder particles during the initial stage of sintering. Induced plasma can remove the diffusion barrier such as surface impurities and oxide layers, resulting in fast densification during SPS. However, the formation of plasma during SPS has not yet been confirmed [3].

Later, the diffusion of atoms powered by the momentum transfer between ions and conducting electrons, referred to as electromigration, was suggested as one of the reasons of the accelerated mass 
transport under SPS conditions. It was shown that pulsed DC current accelerated the inter-particle neck growth between $\mathrm{Cu}$ or $\mathrm{W}$ spheres and plates [4], [5]. However, Trzaska et al. [6], showed no dependence of the new phase growth rate on the electric current density in the Ag-Zn system during the SPS process.

Electroplasticity was generally studied by measuring the stress required to deform fully dense metal specimens with and without electric current at low or high temperatures [7], [8]. The electric current reduces the flow stress of the metal by enhancing the dislocation motion: - this phenomenon was termed "electro plastic effect" (EPE), which describes the facilitated deformation under electric current influence.

A) Metal deformation in electroplasticity theory

Assuming that the plastic deformation of the material is thermally activated, the strain rate can be expressed as follows [9], [10]:

$$
\dot{\gamma}=\dot{\gamma}_{0} \exp \left(\frac{-\Delta G}{k T}\right)=\rho_{m} b \nu_{d} s \exp \left(\frac{-\Delta G}{k T}\right)
$$

where $\rho m$ is the mobile dislocation density, $b$ is the magnitude of the Burgers vector $(m)$, is the frequency of the vibration of the dislocation segment involved in the thermal activation $(1 / \mathrm{s}), \mathrm{s}$ is the average distance of the dislocation travel $(\mathrm{m}), \Delta \mathrm{G}$ is the activation energy $(\mathrm{KJ} / \mathrm{mol}) \mathrm{T}$ is the absolute temperature $(\mathrm{K})$, and $\mathrm{k}$ is Boltzmann constant $(\mathrm{J} / \mathrm{K})$.

Conrad [10] studied the electric field effect on the flow stress of metals ( $\mathrm{Ni}, \mathrm{Ti}, \mathrm{Al}, \mathrm{Cu}$, and $\mathrm{Zn}$ ) at low temperatures and showed that there is the interaction between the drift electrons and dislocations. He showed that the most significant effect of the electrons is on the pre-exponential factor 0 in Eq. (1), which was shown to be proportional to the square of the electric current density $(J)$. This means that the electric current can affect $\rho m$, , As, or . However, it was not determined yet which factor is the most affected by the electric current.

B) Ceramics deformation in electroplasticity theory

Ceramic materials manifest their brittle nature at low temperatures. However, they can have ductile properties at high temperatures [11]. Plastic deformation of ceramic materials is described by Eq. (A.1) in Appendix A. Conrad and Yang studied the electric field effect on the flow stress of oxide ceramics (MgO and $\mathrm{Al}$ 2O3) at high temperatures. Like in the case of metals, the application of the electric field during tensile deformation of oxides reduces their flow stress and the increase of the elongation. They tested the rate controlling constants Acr, $n$, and $p$ in Eq. (A.1) with and without an electric field, and found that the electric current did not change the major deformation mechanism of the material [11], [12], [13]. 
Instead, they assumed that the electric current affected the values of D0 or Q. Also, Conrad and Yang explained that the reduction of the flow stress by an electric current is due to the decrease in the electrochemical potential of the rate limiting vacancies in the space charge clouds near grain boundaries [10].

It was additionally shown that the densification mechanisms of the processed powders may be altered by electric current. Powder materials have certain densification mechanisms depending on the powder particle size, temperature and pressure applied [14]. One way to analyze this is the comparison of the densification behavior under SPS and HP conducted using the same pressure and temperature experimental conditions. Few attempts have been undertaken to find the effect of electric current on the densification mechanism of various materials, yielding conflicting results. Langer et al. [15], [16], [17], compared the densification behavior of ionic conductor, semiconductor, and insulator powders and showed no difference in the densification mechanism using master sintering curve (MSC) approach [18]. In contrast, Maryse et al. [19], utilizing the MSC and Bernard-Granger methods [20], indicated that the electric current changes the densification mechanism of alumina possibly by affecting the grain boundaries of powder particles.

Thus, the above-mentioned analysis of previous studies indicates that SPS is a rapid method for the production of dense ceramic materials. However, the SPS mechanism of rapid densification has not been clearly identified, especially in terms of the effect of the electric current, and mainly due to a number of obstacles, including: (i) the complexity of the deconvolution of the Joule heating and possible nonthermal field phenomena, and (ii) the difficulty of the accurate experimental measurements of the specimen's temperature and electric current parameters during SPS.

To overcome these limitations, a few attempts have been conducted for the investigation of the role of the electric current in the SPS process. Multi-step pressure dilatometry was used to compare the densification mechanism of copper powders with and without electric current assistance using alumina components inside of the SPS tooling setup [21]. The relative density of the densified copper pellets in the current assisted mode was higher than that of the current-insulated mode, yet the densification mechanism was the same for both cases. A possible reason for this experimental outcome was that, instead of using the temperature of the powder, the temperature of the graphite die was used for controlling the SPS regime and for analyzing the experimental data, thereby leading to the inaccurate deduction of the densification mechanism of the copper powder. More sophisticated deconvolution of the temperature from the electric current was implemented by the sinter-forging setup in SPS [22]. The sample temperature was directly measured by a thermocouple introduced through a hole in the graphite die. In situ axial punch displacement was recorded by SPS, and the lateral deformation of the specimen was recorded by a video camera. It was revealed that the current-assisted case leads to a higher 
densification compared to the current insulated case. However, the electric current effects on the densification mechanism of the copper were not quantitatively assessed.

In SPS process, if the powder is electrically conductive, a significant fraction of the electric current can pass through it, so that the temperature of the powder becomes higher than that of the die. As opposed to conventional approaches, when SPS control temperature is measured at a selected point in the die wall, special techniques are required to determine the actual temperature of the powder for conductive materials subjected to SPS. Unfortunately, an accurate quantitative assessment of the fraction of the electric current passing through a powder sample during SPS is hard to obtain due to the difficulties of the measurement of the electric current inside of the die. Finite element modeling (FEM) of SPS has been used for the estimation of the temperature and electric current distribution inside the die-punch set during SPS [23], [24], [25].

Zirconium nitride $(\mathrm{ZrN})$ is used as a material whose electric current-affected densification behavior during SPS is investigated. ZrN has been attracting increasing attention over the last decades, due to the combination of excellent thermal, mechanical and electrical properties. Densification of ZrN was studied for free sintering, HP, SPS and high voltage electric discharge consolidation (HVEDC), and the summary of the obtained results has been published [26]. Compared with other ceramic materials which have high electric resistivity at room temperature, ZrN has lower electrical resistivity $(\sim 50 \mu \Omega \mathrm{cm})$ with positive temperature coefficient (PTC) behavior indicating more metallic-like properties [27], [28].

In the conducted study, SPS and HP consolidation experiments of ZrN have been carried out under the same pressure and temperature conditions. In order to identify the actual temperature during SPS, an independent experiment has been performed with a thermocouple directly inserted into ZrN powder during SPS. The parameters of the electric current passing through ZrN powder were calculated using a FEM simulation. For finding the densification mechanism of $\mathrm{ZrN}$, the constitutive equations for the hot pressing of powders have been modified to take into account the explicit electric current effect on SPS.

\section{Experimental procedures}

For all SPS and HP experiments, ZrN powders $(\mathrm{Fm} 3 \mathrm{~m})$ produced by Sigma-Aldrich with average particle size of $6.71 \mu \mathrm{m}$ were employed.

The sintering experiments were carried out using the SPS device manufactured by SPS Syntex Inc., model Dr. Sinter SPSS-515 with a Poco EDM4 graphite tooling setup. The detailed information on the powder, tooling setup and SPS device can be found elsewhere [26]. 
Optical pyrometer and k-type thermocouple can measure temperature within the ranges from $570{ }^{\circ} \mathrm{C}$ to $3000{ }^{\circ} \mathrm{C}$ and from room temperature to $1200^{\circ} \mathrm{C}$ respectively. However, the pyrometer generally showed non-accurate temperature values compared with those measured by the thermocouple; also it could not be used within the low-temperature range. At the same time, the exact temperature of ZrN powders during SPS should be identified to ensure the correct determination of the densification mechanism. Firstly, the graphite die temperature was measured by an optical pyrometer and a k-type thermocouple at the same time. PID (proportional-integral-derivative) control of the SPS system was accomplished using the pyrometer aimed at the $2.5 \mathrm{~mm}$ deep hole in the die, and, at the same time, another k-type thermocouple detected the die temperature in another hole of the same die which was recorded by the extra thermometer (die temperature by pyrometer and thermocouple in the Fig. 1(a)). Secondly, for obtaining the exact temperature inside the specimen, the sheath protected k-type thermocouple was directly inserted into the powder ( $\mathrm{rNN}$ temperature by thermocouple in the Fig. 1(a)) and, at the same time, SPS machine was operated by the temperature of the die hole measured by pyrometer (die temperature by pyrometer in the Fig. 1(a)) [29]. The thermocouple was inserted through a center hole in the upper graphite punch. Another SPS experiment under the same temperature and pressure conditions was conducted without inserting the thermocouple to obtain the densification curve of the powder and thus, without eventual disturbances of the electrical and temperature fields imposed by the thermocouple inserted in the powder.
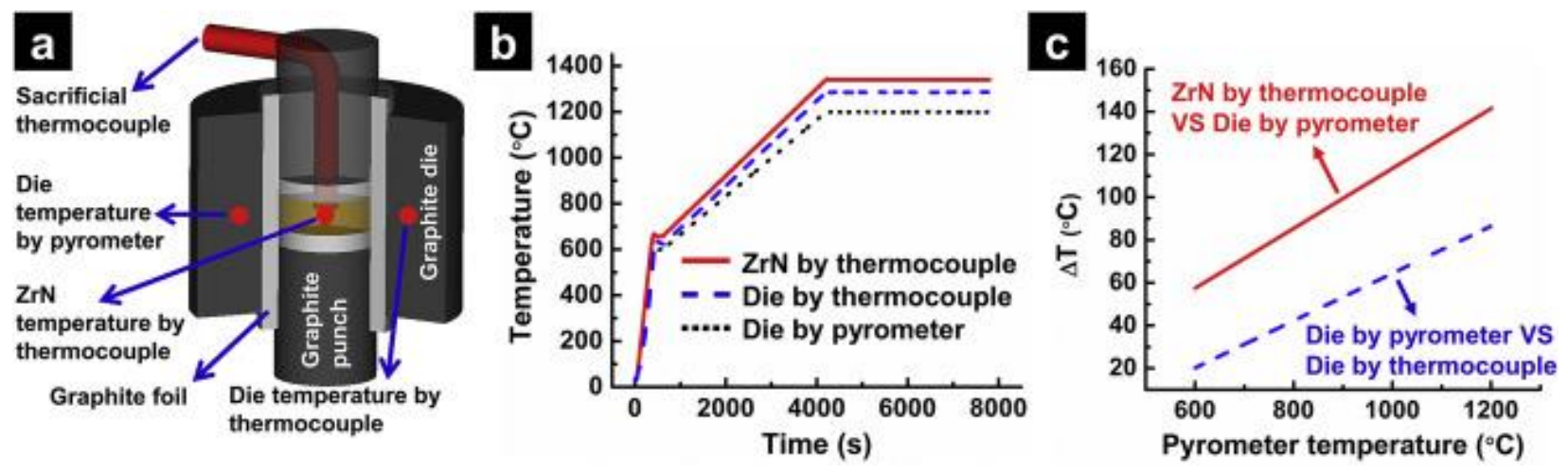

Fig. 1. (a) Schematics of SPS setup with temperature measurement points, (b) Temperature evolution of different measurement spots: SPS at $1200^{\circ} \mathrm{C}$ under $60 \mathrm{MPa}$ and $10^{\circ} \mathrm{C} / \mathrm{min}$ (red solid line: $\mathrm{ZrN}$ temperature by thermocouple, blue dash line: die temperature by thermocouple, black dot line: die temperature by pyrometer), (c) Differences $(\Delta T$ ) between $\mathrm{ZrN}$ temperature measured by thermocouple and die temperature measured by pyrometer (red solid line), and between die temperature measured by pyrometer and die temperature measured by thermocouple (blue dash line). (For interpretation of the references to colour in this figure legend, the reader is referred to the web version of this article.)

HP of the powders was carried out by a $1000 \mathrm{~kg}$ hot press furnace (Oxy-Gon Industries, Epsom, NH, USA). The heating in HP is transferred by radiation and conduction from the heating element outside of the graphite setup, resulting in more homogenized temperature distribution between the die and powder. 
Therefore, we assumed that the temperature of $\mathrm{ZrN}$ and the graphite die are the same for the HP process.

The measured initial green density of the powder compacts was $\sim 58 \%$ for $60 \mathrm{MPa}$ uniaxial pressure in the SPS and HP chambers before starting the sintering. The same heating cycle was used to compare the HP and SPS densification behaviors of ZrN. The experimental conditions and the representative results of the SPS and HP experiments are listed in Table 1. All experiments were conducted with purged argon gas.

Table 1. The experimental conditions and physical properties of ZrN specimens prepared by SPS and HP.

\begin{tabular}{|c|c|c|c|c|c|c|c|}
\hline Name & Set $\mathbf{T}^{\mathrm{a}}$ & $\mathbf{T}(\mathbf{Z r N})^{b}$ & Pressure & Holding time & Heating rate & Relative density & Grain size \\
\hline Exp. setup & ${ }^{\circ} \mathbf{C}$ & ${ }^{\circ} \mathbf{C}$ & MPa & $\min$ & ${ }^{\circ} \mathrm{C} / \mathrm{min}$ & $\%$ & $\mu \mathbf{m}$ \\
\hline SPS & 1100 & 1225 & 60 & 60 & 10 & 92.74 & 7.7 \\
\hline SPS & 1200 & 1340 & 60 & 60 & 10 & 96.45 & 11.88 \\
\hline SPS & 1200 & 1340 & 60 & 60 & 100 & 98.05 & 13.69 \\
\hline SPS & 1300 & 1453 & 60 & 60 & 10 & 98.92 & 24.34 \\
\hline SPS & 1500 & 1683 & 60 & 30 & 10 & 99.81 & 36.55 \\
\hline HP & 1200 & 1200 & 60 & 60 & 10 & 80.44 & 7.67 \\
\hline HP & 1500 & 1500 & 60 & 60 & 10 & 98.19 & 21.79 \\
\hline HP & 1900 & 1900 & 60 & 60 & 13 & 99.42 & 59.71 \\
\hline
\end{tabular}

Set $\mathrm{T}$ is the maximum programmed temperature at the die hole in the SPS or HP devices.

$\mathrm{b}$

$\mathrm{T}(\mathrm{ZrN})$ is the temperature measured or estimated by inserting the thermocouple into ZrN during SPS.

The relative density was estimated by the Archimedes' immersion method. The fractured or polished specimens were analyzed by the scanning electron microscopy (FEI Quanta 450, USA).

\section{Experimental results and discussion}

The experimental conditions and physical properties of the $\mathrm{ZrN}$ specimens compacted by SPS and HP are listed in Table 1. Full density was achieved under both SPS and HP with different maximum temperatures, $1500{ }^{\circ} \mathrm{C}$ for SPS and $1900^{\circ} \mathrm{C}$ for HP, which means that SPS showed faster densification and lower densification temperature. However, this result may have been caused by the direct Joule heating of the electrically conductive $\mathrm{ZrN}$ powder. Also, the densification could have been affected by a possible electric current effect. 
The following two experimental factors should be accurately determined for elucidating the electric current effect on the powder densification mechanism: (a) the powder temperature and (b) the electric current density in the powder, located inside of the graphite die during SPS. In addition, one needs (c) a modeling concept for the evaluation of the densification mechanism considering the electric current effect.

\subsection{Temperature calibration for SPS}

The pyrometer measured the temperature until the final temperature was reached, and the sacrificial ktype thermocouple embedded in $\mathrm{ZrN}$ powder was melted and finally broken at $1250^{\circ} \mathrm{C}$. Temperatures $>1250^{\circ} \mathrm{C}$ were estimated by the fitting equation based on the calibration experiments $\left(\mathrm{T}>600^{\circ} \mathrm{C}\right)$.

Compared with the die temperature readings from the pyrometer, the die and powders measured by thermocouple showed higher temperatures during the SPS cycle: $1200^{\circ} \mathrm{C}$ under $60 \mathrm{MPa}$ and $10^{\circ} \mathrm{C} / \mathrm{min}$ (Fig. 1(b)). For example, at $1200^{\circ} \mathrm{C}, \Delta \mathrm{T}$ between $\mathrm{ZrN}$ and die is $141^{\circ} \mathrm{C}$ (Fig. 1 (c)). The location of the sample in the SPS die set is more favorable to heat accumulation compared with the die surface, which is the heat dissipation area. Ceramic material like alumina also showed similar temperature differences supporting our observations [30]. The concentrated current flow in the center of the powder specimen should increase the direct Joule heating, which can be another factor causing the temperature difference between the die and specimens.

Fig. 2 shows porosity evolution during the whole processing cycle for the sintered specimens obtained from the two experiments: SPS at $1100^{\circ} \mathrm{C}$ and $\mathrm{HP}$ at $1200^{\circ} \mathrm{C}$. Experimental conditions, including heating rate, applied uniaxial pressure, and atmosphere, as well as the amounts of powder utilized per specimen, were the same. For the SPS, the actual ZrN temperature inside of the die at the holding stage is $1225^{\circ} \mathrm{C}$; that was $25^{\circ} \mathrm{C}$ higher compared with the HP case $\left(1200^{\circ} \mathrm{C}\right)$. SPS showed faster densification (Fig. 2(a)) and a more consolidated structure compared with HP (Fig. 2(b) and (c)). The $25{ }^{\circ} \mathrm{C}$ temperature difference is not sufficient to explain the final density difference of $12.30 \%$ between SPS and HP. Therefore, the electric current flowing into ZrN powder during SPS can be a possible factor contributing to the difference in porosity evolution shown in Fig. 2(a). 

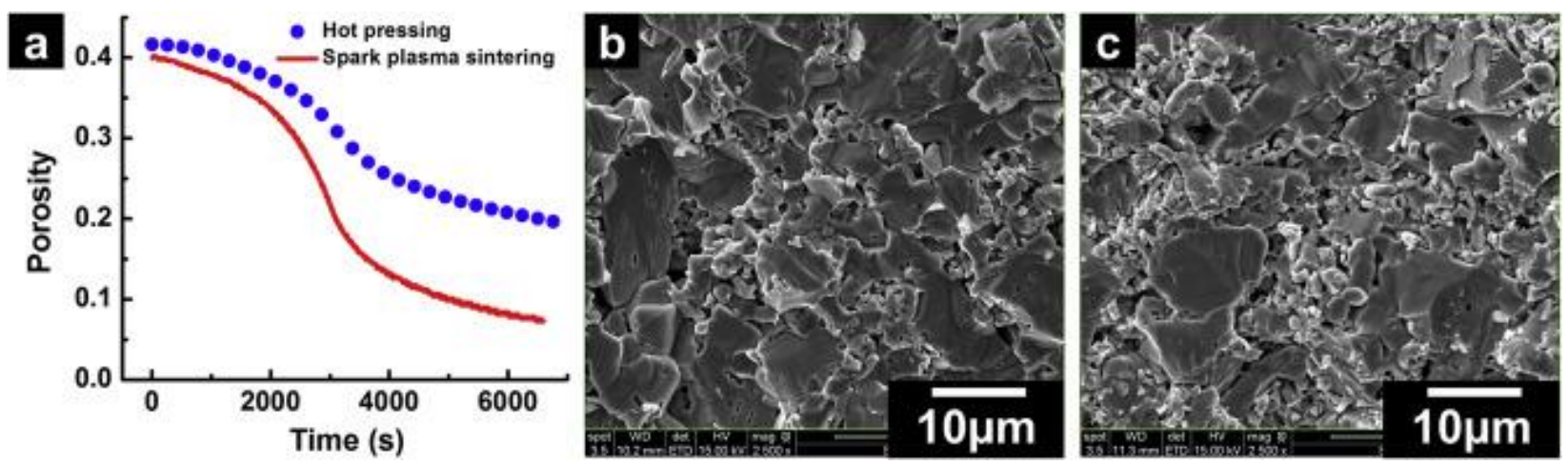

Fig. 2. (a) Porosity variation of $\mathrm{ZrN}$ powder densified (60 MPa and $10^{\circ} \mathrm{C} / \mathrm{min}$ ) by SPS $\left(1100^{\circ} \mathrm{C}\right.$ ) and $\mathrm{HP}$ $\left(1200^{\circ} \mathrm{C}\right)$; images of the fractured surface of samples densified by (b) SPS at $1100^{\circ} \mathrm{C}$ and (c) HP at 1200 ${ }^{\circ} \mathrm{C}$.

\subsection{Assessment of the electric current density in the powder specimen's volume}

The total electric current values recorded by the SPS system are not identical to the amount of the electric current (IS) passing through the samples during SPS. Is is mainly affected by the electrical and thermal properties of the die set. An electro-thermal model based on the finite element code COMSOL ${ }^{\mathrm{TM}}$ has been developed within the framework of the present studies to estimate the Is during SPS. The entire vertical assembly of the SPS tooling setup including the graphite die, punches, sample, and electrodes are analyzed in the model. The properties of the materials considered are given in Table 2 . The properties of $\mathrm{ZrN}$ were obtained from the literature [27], [31], and the electrical and thermal conductivity were modified by the effective medium approximation method [32], [33]. The detailed boundary conditions of the FEM simulations have been previously described [24].

Table 2. Physical properties of graphite, $\mathrm{ZrN}$ and stainless steel 304 (with T in Kelvin).

\begin{tabular}{|c|c|c|c|c|}
\hline \multirow[t]{2}{*}{ Material } & Electrical conductivity & Heat capacity & $\begin{array}{l}\text { Thermal } \\
\text { conductivity }\end{array}$ & Density \\
\hline & $\mathbf{S} / \mathbf{m}$ & J/(kgK) & $\mathbf{W} /(\mathbf{m K})$ & $\mathbf{k g} / \mathbf{m}^{3}$ \\
\hline Graphite [67] & $\begin{array}{l}29.40^{*} 10^{3}+208.84 \mathrm{~T}- \\
16.77^{*} 10^{-2} \mathrm{~T}^{2}+5.24^{*} 10^{-5} \mathrm{~T}_{3-} \\
5 \cdot 90^{*} 10^{-9} \mathrm{~T}_{4}\end{array}$ & $\begin{array}{l}-280.03+4.16 \mathrm{~T}- \\
2.91^{*} 10^{-3} \mathrm{~T}^{2}+9.30^{*} 10^{-7} \mathrm{~T}^{3-} \\
1.11^{*} 10^{-10} \mathrm{~T}_{4}\end{array}$ & $\begin{array}{l}161.63^{-} \\
1.79^{*} 1 \mathrm{O}^{-1} \mathrm{~T}+1.07^{*} 1 \mathrm{O}^{-4} \mathrm{~T}^{2-} \\
2.43^{*} 1 \mathrm{O}^{-8} \mathrm{~T} 3\end{array}$ & 1740 \\
\hline $\mathrm{ZrN}$ & $\begin{array}{l}3.23^{*} 10^{8} \mathrm{~T}-0.804 *(1- \\
(3 / 2) \theta)[27]\end{array}$ & $\begin{array}{l}\left(45.86+6.82^{*} 10^{-3} \mathrm{~T}-\right. \\
\left.5 \cdot 54^{*} 10^{5} / \mathrm{T}^{-2}\right) / 0.11^{*}(1- \\
\theta)[31]\end{array}$ & $\begin{array}{l}\left(28.30+1.20^{*} 10^{-2} \mathrm{~T}-\right. \\
\left.3 \cdot 7^{*} 10^{-6} \mathrm{~T}^{2}\right)^{*}(1- \\
(3 / 2) \theta)[31]\end{array}$ & $\begin{array}{l}7090 *(1- \\
\theta)\end{array}$ \\
\hline $\begin{array}{l}\text { Stainless } \\
\text { steel } \\
304[68]\end{array}$ & $\begin{array}{l}\left(50.17+8.38^{*} 10^{-2} \mathrm{~T}-\right. \\
\left.1.75^{*} 10^{-5} \mathrm{~T}^{2}\right)^{*}\left(1.00^{*} 10^{-8}\right)\end{array}$ & $446.50+1.62^{*} 10^{-1} \mathrm{~T}$ & $9.99+1.75^{*} 10^{-2} \mathrm{~T}$ & 7900 \\
\hline
\end{tabular}


Vertical and horizontal electrical contact resistances (ECR) were obtained using previous results [34]. Also, the thermal contact resistances (TCR) were used in accordance with previous work [30]. After developing the FEM model, the temperature values measured in the die and inside the powder from the start until the onset of cooling were used to calibrate the ECR and TCR at the $\mathrm{ZrN}$-graphite interfaces. Both contact resistances affect the thermal behavior during the ramping and holding stage. Otherwise, the cooling stage (purely thermal) is suitable for adjusting the TCR.

The vertical and horizontal contact resistances were disregarded in previous studies [35], [36]. However, the vertical contact resistance has an important impact on the magnitude of the fraction of the electric current passing through the conductive powder. Without the consideration of the vertical ECR and TCR, the simulated temperatures for the die and sample during the holding stage are $138^{\circ} \mathrm{C}$ and $172{ }^{\circ} \mathrm{C}$ lower than the experimentally measured temperatures (Fig. 3(a)), which means that the ECR-and TCR-related heat dissipation should be considered. Also, the major fraction of the electric current appears to flow through the die (Fig. 3(b)).

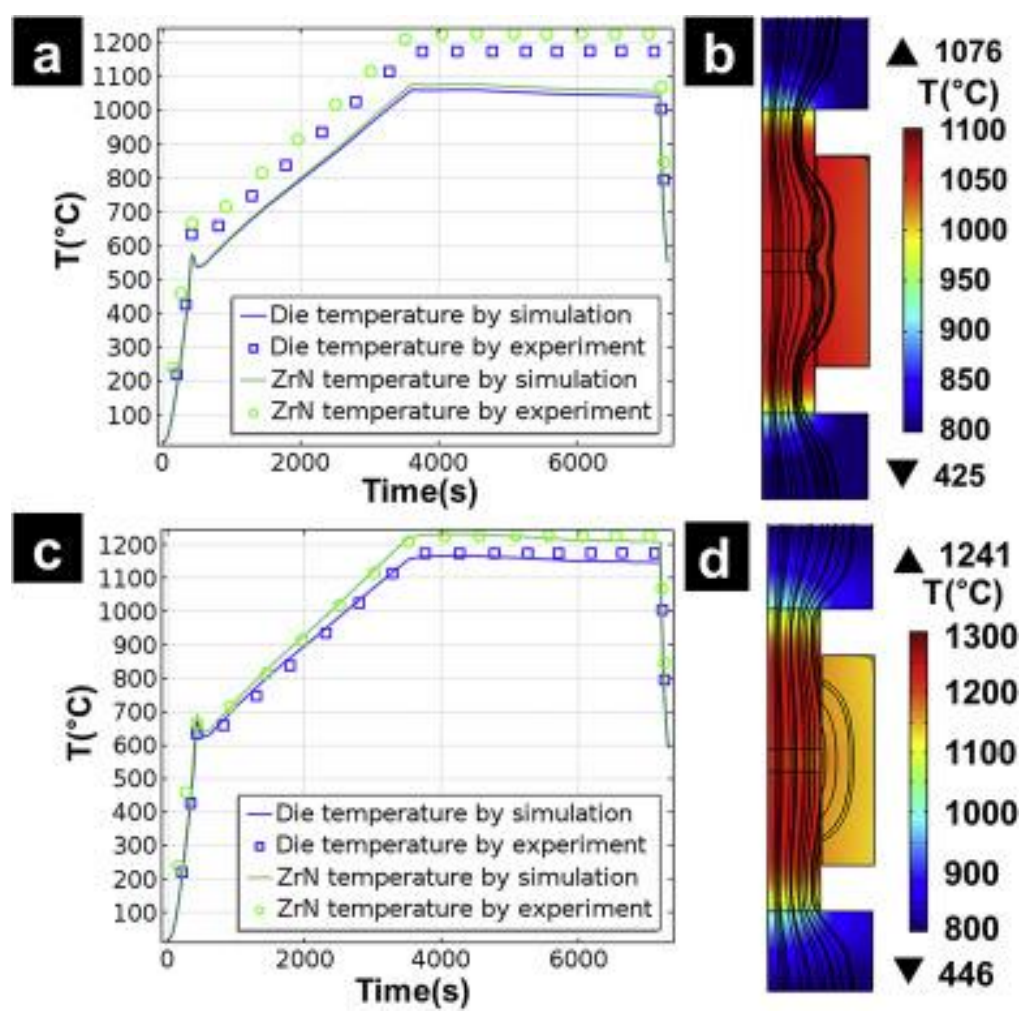

Fig. 3. Experimentally measured and FEM-simulated temperatures of ZrN powder and graphite die during SPS thermal cycle (a) without contact resistance, (c) with electrical and thermal contact resistance. FEM simulation map of the temperature and electric current flow at the end of the holding time (b) without contact resistance, (d) with electrical and thermal contact resistance. SPS at $1100{ }^{\circ} \mathrm{C}$ under $60 \mathrm{MPa}$ and $10^{\circ} \mathrm{C} / \mathrm{min}$ was used. 
As shown in Fig. 3(c), the results of the modeling considering the vertical ECR and TCR and their calibration are close to the experimentally measured and simulated temperatures. The calibrated ECR and TCR equations are shown in the Eq. (2) below. The electric current from the top punch was split, and the high portion of electric current passed through the powder during the holding stage (Fig. 3(d)). Also, a non-homogenous temperature distribution between the die and the central column of the tooling set (punches and powder) was observed due to the presence of the contact resistance (Fig. 3(d)).

$$
\begin{aligned}
& E C R_{Z r N / \text { graphite }} \\
& =\left(\left(-5.70 * 10^{-3} *(T-273)+18.6\right) *\left(-7.90 * 10^{-3} P+1.14\right) *\left(1.00 * 10^{-7}\right)\right) \\
& * 0.3\left(\text { Ohm } \cdot m^{2}\right) \\
& T C R_{Z r N / \text { graphite }}=1.50 * 10^{-4} /\left(162-0.179 T+1.07 * 10^{-4} T^{2}-2.43 * 10^{-8} T^{3}\right) \\
& \left(K \cdot m^{2} / W\right)
\end{aligned}
$$

\subsubsection{Overall Local Electric Current Density (OLECD) estimation for powder samples}

Current density in a powder sample is mainly affected by the neck area between particles during the SPS. The neck area changes with porosity evolution, has been studied by Helle, Artz, and Ashby [37], [38]. Current density can be large at the initial stage of sintering (small neck) and reduces with decreasing porosity (large neck) during sintering.

For an irregular packing of the spherical particles, the neck area evolution with porosity can be estimated as shown by Helle et al. [38]:

$$
\frac{A Z}{4 \pi R^{2}}=\frac{\left(\theta_{0}-\theta\right)(1-\theta)}{\theta_{0}}
$$

where A: average area of contacts between two particles, Z: coordination number, R: particle radius, $\theta 0$ : initial porosity and $\theta$ : porosity. When $R$ is constant, $A Z / 4 R 2$ value is increased from 0 to 1 when porosity is changed from $\theta 0$ to 0 (Fig. 1 in Ref. [38]). We assume that the neck area evolution of one particle is proportional to the total contact area change of the total powder specimen's volume. Therefore, we consider $A Z / 4 \pi R 2$ to be the ratio of the total neck area to the total powder surface area. Overall local electric current density (OLECD) is the summation of the electric current density of all necks in the powder volume.

Using the previous consideration, JOL (OLECD) of the sample can be calculated as follows:

$$
J_{O L}=\frac{I_{s}}{A_{\text {cross sec tion }}} \times \frac{4 \pi R^{2}}{A Z}
$$

where Across-section: cross-sectional area of the full density sample. 
Fig. 4 shows the electric current density change during SPS experiments for (a) $1200{ }^{\circ} \mathrm{C}, 60 \mathrm{MPa}$ and 10 ${ }^{\circ} \mathrm{C} / \mathrm{min}$ and (b) $1200{ }^{\circ} \mathrm{C}, 60 \mathrm{MPa}$ and $100^{\circ} \mathrm{C} / \mathrm{min}$. The black line represents the electric current density evolution with (dash-dot line) and without (dot line) consideration of the neck area change. The blue line represents. For all the conducted SPS experiments, the temperature stabilization steps during SPS runs include the ramping from room temperature to $580^{\circ} \mathrm{C}$ for $6 \mathrm{~min}\left(93^{\circ} \mathrm{C} / \mathrm{min}\right)$, ramping from $580{ }^{\circ} \mathrm{C}$ to 600 ${ }^{\circ} \mathrm{C}$ for $1 \mathrm{~min}$, and soaking at $600{ }^{\circ} \mathrm{C}$ for $3 \mathrm{~min}$. After these steps, the ramping to the maximum temperature at $10^{\circ} \mathrm{C} / \mathrm{min}$ or $100^{\circ} \mathrm{C} / \mathrm{min}$ and holding step is used.
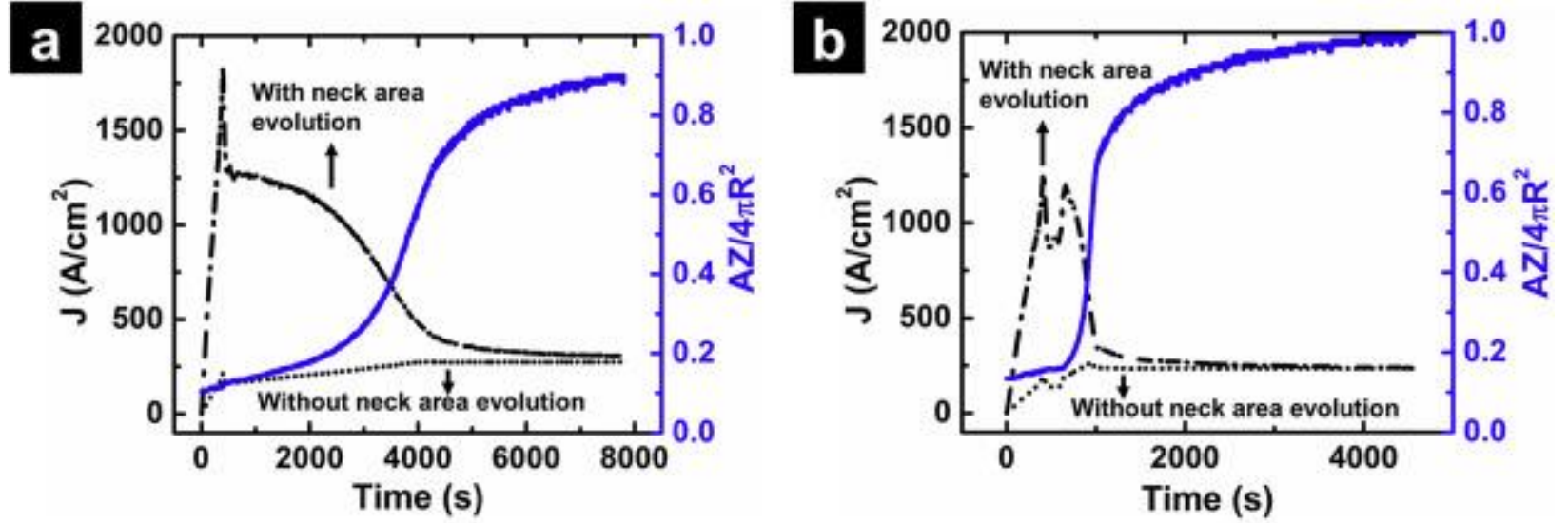

Fig. 4. Current density evolution with (black dash-dot line) and without (black dot line) consideration of the neck area change during the whole SPS cycle. Neck area evolution is shown with respect to the right $\mathrm{y}$-axis (blue solid line). (a) SPS, $1200^{\circ} \mathrm{C}, 60 \mathrm{MPa}$ and $10^{\circ} \mathrm{C} / \mathrm{min}$ and (b) SPS, $1200^{\circ} \mathrm{C}, 60 \mathrm{MPa}$ and 100 ${ }^{\circ} \mathrm{C} / \mathrm{min}$. Electric current through the sample (Is) from the FEM simulation were used. (For interpretation of the references to colour in this figure legend, the reader is referred to the web version of this article.)

The low heating rate SPS showed the highest OLECD peak with the overheating around $580{ }^{\circ} \mathrm{C}$ and decreased OLECD during ramping to the maximum temperature and holding stage (black dash-dot line in Fig. 4(a)). Higher heating rate SPS showed two high OLECD peaks at $580^{\circ} \mathrm{C}$ and $1200^{\circ} \mathrm{C}$ due to overheating at the end of the ramping stage (Fig. 4(b)). Especially, the integral of OLECD (area under the black solid line) is small for high heating rate SPS, which implicates that overall electric current effects can be small.

\subsection{Constitutive equation for sintering taking into account the electric current effect}

\subsubsection{Electroplasticity theory}

Fig. 2(a) curves resemble the electro-plasticity experiments which showed a lowered yield stress when passing an electric current during the deformation of metals [39], [40]. In the present study, the constitutive equation of the continuum theory of sintering was modified to include the electric current effect term based on the recent results of the electroplasticity theory [10], [41], [42]. The existence and movement of dislocations in ceramic and metal structures, such as zirconium oxycarbide [43], B4C [44], and TiAl [45] compacted by SPS, have been reported. Generally, the mass transfer constitutive 
parameters include the strain rate sensitivity $m$ (or its reciprocal - stress exponent $n$ ) and activation energy of creep $Q$, as summarized elsewhere [46].

\subsubsection{Constitutive equation for SPS}

We assume that the reduction of the particle material yield stress by an electric current is a major mechanism of the rapid densification of conductive powders compacted via an electric current-assisted consolidation method. The reduction of the yield stress can be achieved mainly by the two effects induced by the electric current: (i) local Joule heating, (ii) electron wind effect.

(i)Local Joule heating effect

When the electric current flows through a powder during deformation, the local "hot spots" caused by the greater electron scattering at defects such as dislocations, voids, impurities and grain boundaries, largely enhance the lattice vibration energy in the defect vicinity. As a result, dislocations can move more easily along the slip plane bypassing lattice obstacles with smaller resistance. Therefore, the stress required to move dislocations is reduced. This heating occurs at the atomic level within the lattice contributing to the total heating of the sample, and expanding the lattice locally [41], [47]. Hence, the local Joule heating increases parameters vd and $\rho m$ in Eq. (1). This effect can lead to faster defect motion under SPS compared with HP conditions. While HP needs external energy in ut that have to heat the entire material to allow for the dislocations to diffuse to a sink such as grain boundaries, SPS provides a greater amount of energy in a faster mode and directly to the dislocations. Also, recently, using the modified Williamson-Hall method [48], [49], the XRD method indirectly showed that an increasing electric current density decreased the dislocation density of a tungsten pellet compacted by SPS, which indicated the dislocation mobility enhanced by the electric current influence [50].

(ii)Electron wind effect

The direct momentum transfer from flowing electrons through the electric conductor can help the mobility of dislocations in the lattice structure [8], [51]. However, some researchers showed that the electron wind effect is not sufficient to affect the dislocation activities [52], [53]. In particular, Salandro et al. [41], showed that the added energy to a dislocation core by the electron wind effect is much less than that by the local Joule heating effect.

Therefore, one can assume that the main source of the reduction of the flow stress by the electric current is from the indirect local vibration energy from electron scattering, not from the direct momentum transfer to the dislocation.

The constitutive equation describing hot pressing of a nonlinear viscous porous material in a rigid die can be written as [54], [55], [56]:

$$
\dot{\theta}=-\left[\frac{G}{A_{0} T}\left(\frac{b}{d}\right)^{p} \exp \left(\frac{-Q}{R T}\right)\right]\left(\frac{3 \theta}{2}\right)^{\frac{m+1}{2 m}}(1-\theta)^{\frac{m-3}{2 m}}\left(\frac{\sigma_{z}}{G}\right)^{\frac{1}{m}}
$$


where is the densification rate $(1 / \mathrm{s}), \mathrm{G}$ is the shear modulus (MPa), $d$ is the grain size $(\mathrm{m}), \mathrm{p}$ is the grain size exponent, $Q$ is the creep activation energy $(\mathrm{KJ} / \mathrm{mol})$, and $R$ is the gas constant $(\mathrm{J} / \mathrm{molK})$, is the $Z$-axis applied stress (MPa) and $A 0$ is the material constant (Pa.s/K). The derivation of Eq. (5) is described in Appendix A.

In Eq. (5), we define the function in the square bracket as ATD (1/s) which indicates the thermal deformability of the powders during the sintering.

$$
A_{T D}=\frac{G}{A_{0} T}\left(\frac{b}{d}\right)^{p} \exp \left(\frac{Q}{R T}\right)
$$

Total equivalent effective strain rate $(\mathrm{W})$ should be the sum of the strain rate from thermal and electric current assisted effect during the SPS process.

$$
W=W_{\text {Thermal }}+W_{\text {Electric current assisted }}
$$

Using Eq. (A.3), Eq. (7) is converted with the introduction of AECAD (1/s) which indicates the electric current assisted deformability of the powders as follows:

$$
W=\left(A_{T D}+A_{E C A D}\right)\left(\frac{\sigma_{z}}{G}\right)^{\frac{1}{m}}
$$

By substituting Eqs. (A.6), (A.7), (A.8), (A.9), (8) into Eq. (A.5) and taking into account that = 0 (uniaxial die compaction boundary condition), the constitutive equation for SPS can be written as

$$
\dot{\theta}=-\left[A_{T D}+A_{E C A D}\right]\left(\frac{3 \theta}{2}\right)^{\frac{m+1}{2 m}}(1-\theta)^{\frac{m-3}{2 m}}\left(\frac{\sigma_{z}}{G}\right)^{\frac{1}{m}}
$$

Also, Eq. (9) is validated based on the electroplasticity theory which indicates that the electric current affects the pre-exponential factor for metals, and Do or Q for ceramic materials [9], [10], [11], [12].

To find AECAD, the following analysis is used. Local Joule heating can provide the vibration energy to the dislocation movement [41]. Also, high temperature of the locally overheated region may be sufficient to activate additional intrinsic defects [57]. These generated defects can enhance the mobility of dislocations by interacting with elastic and electronic fields of the dislocations [9], [58], [59], but more interestingly, can be also the source of the local Joule heating, making the local temperature to increase again, and thereby starting the cascade effects. However, due to the relatively low electric current density under regular SPS conditions and being coupled with vacancy annihilation by dislocation movement, these cascade effects are limited compared to flash sintering [60], [61]. 
Therefore, we assume that the energies of the local Joule heating are the original source for the electric current effects. The actual temperature of the sample was calibrated previously in the experiments, but the additional Joule heating effects like the defect generation should be accumulated with sintering time during SPS due to the cascade characteristics. The localized energy provided to the dislocation core due to the Joule heating effect (per dislocation core volume) is given by Ref. [41]:

$$
E_{J}=J^{2} \lambda_{d} \Delta t
$$

where $\mathrm{J}$ is electric current density, $\lambda \mathrm{d}$ is electrical resistivity of the dislocation core and $\Delta \mathrm{t}$ is the time duration when the electric current is applied. Parameter $\lambda d$ was determined to be around $6-8$ times the electric resistance of the defect-free lattice ( $\lambda$ ) [62]. Also, the dislocation movement by Joule heating can be hindered by Peiers-Nabarro stress () of each material. For the FCC material like ZrN, experimental results showed that is approximately (10-6 10-5)G [63].

Including the terms that affect the dislocation movement considered above, AECAD can be written as:

$$
A_{E C A D}=\left[\int_{t_{0}}^{t_{f}} \frac{J^{2} \lambda_{d}}{\tau_{P N}} d t\right]^{\omega}
$$

where t0, tf are the starting and final time for SPS and $\omega$ is the electric current sensitivity exponent (material constant).

By including the electric current effect coefficient $(\beta)$, which involves the relationships between JOL vs. actual $J$ in the sample, $\lambda d$ vs. actual $\lambda$, and vs. G, Eq. (11) can be written as:

$$
A_{E C A D}=\beta^{\omega}\left[\int_{t_{0}}^{t_{f}} \frac{J_{O L}{ }^{2} \lambda}{G} d t\right]^{\omega}
$$

Therefore, the constitutive equation for SPS, Eq. (9) can be expressed as:

$$
\dot{\theta}=-\left[\frac{G}{A_{0} T}\left(\frac{b}{d}\right)^{p} \exp \left(\frac{Q}{R T}\right)+\beta^{\omega}\left[\int_{t_{0}}^{t_{f}} \frac{J_{O L}{ }^{2} \lambda}{G} d t\right]^{\omega}\right]\left(\frac{3 \theta}{2}\right)^{\frac{m+x}{2 m}}(1-\theta)^{\frac{m s}{2 m}}\left(\frac{\sigma_{z}}{G}\right)^{\frac{1}{m}}
$$

\subsubsection{Sintering "trajectory"}

Grain growth can affect the densification behavior of a powder during sintering [46], [55]. Fig. 5 shows the variation of the grain size as a function of relative density for the different heating rates, holding temperatures and times (data are also taken from the previous ZrN SPS consolidation studies [26]). The 
SEM images of the polished or fractured ZrN specimens are shown in Fig. 1 and Fig. S3 in Supplementary Material. Densification is favored when no grain growth is present until the relative density value of $\sim 92 \%$ is achieved and when the grain size is $\sim 7 \mu \mathrm{m}$, similar to the average size of the raw powder particles. Thus, when the relative density is less than $\sim 92 \%, p=0$ in Eqs. (5), (6), (A.1), (A.10), (A.2), (A.3), (A.4), (A.5), (A.6), (A.7), (A.8), (A.9), (13).

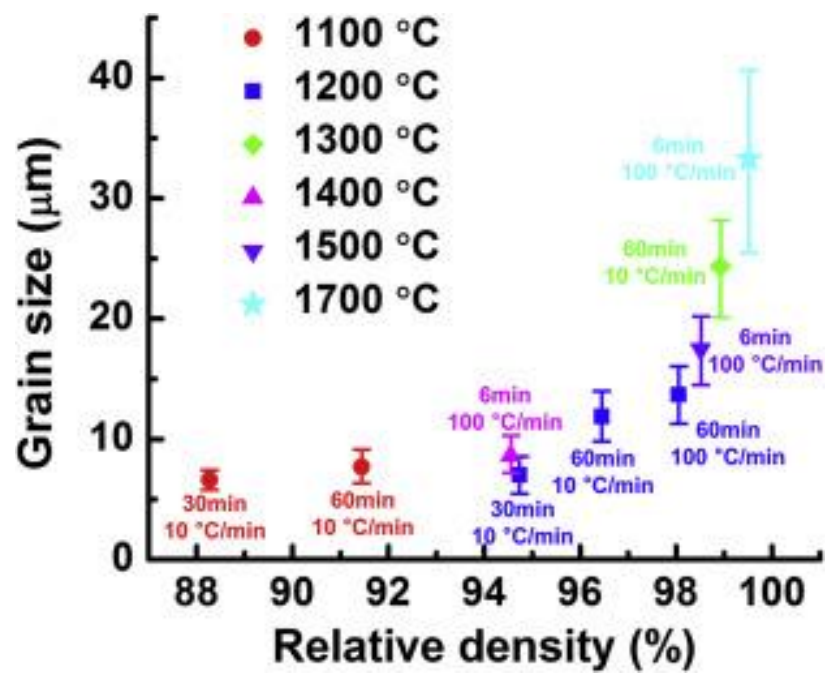

Fig. 5. Grain size as a function of the relative density of ZrN powder pellets obtained by SPS under 60 MPa.

\subsubsection{Densification mechanism of $\mathrm{ZrN}$ with and without electric current effects}

Previously, the sintering for ZrN consolidated by HP was studied by Petrykina and Shvedova [64], indicating that HP has the dislocation climb controlled creep mechanism ( $n=4-5, m=0.2-0.25$ ) with average $Q$ of $142.26 \mathrm{~kJ} / \mathrm{mol}$. To confirm the HP results from Ref. [64], the ranges of parameters $\mathrm{m}$ and $\mathrm{Q}$ were also calculated by modifying Eq. (5) (see Supplementary Materials).

When fitting Eq. (5) (constitutive equation of HP) into experimental porosity evolution data from HP and SPS, if the $m$ value from SPS is not the same as during HP, then these results indicate that the densification mechanism is affected by electric current effects.

Table 3 summarizes the range of the obtained fitting parameters $(\mathrm{m}, \mathrm{Q}$, and $\mathrm{A} 0)$ and the correlation parameter (R2), using the constitutive equation fitting (Eq. (5)) into the experimental porosity time evolution curve during holding stages of HP and SPS. Fig. 6(a) shows the representative fitting results. The experimental densification curves were drawn by the scattered symbols, while the curves defined by a solid line denote the fitting curve. 
Table 3. Summary of the fitting parameters for HP and SPS of ZrN. R2 is the correlation coefficient.

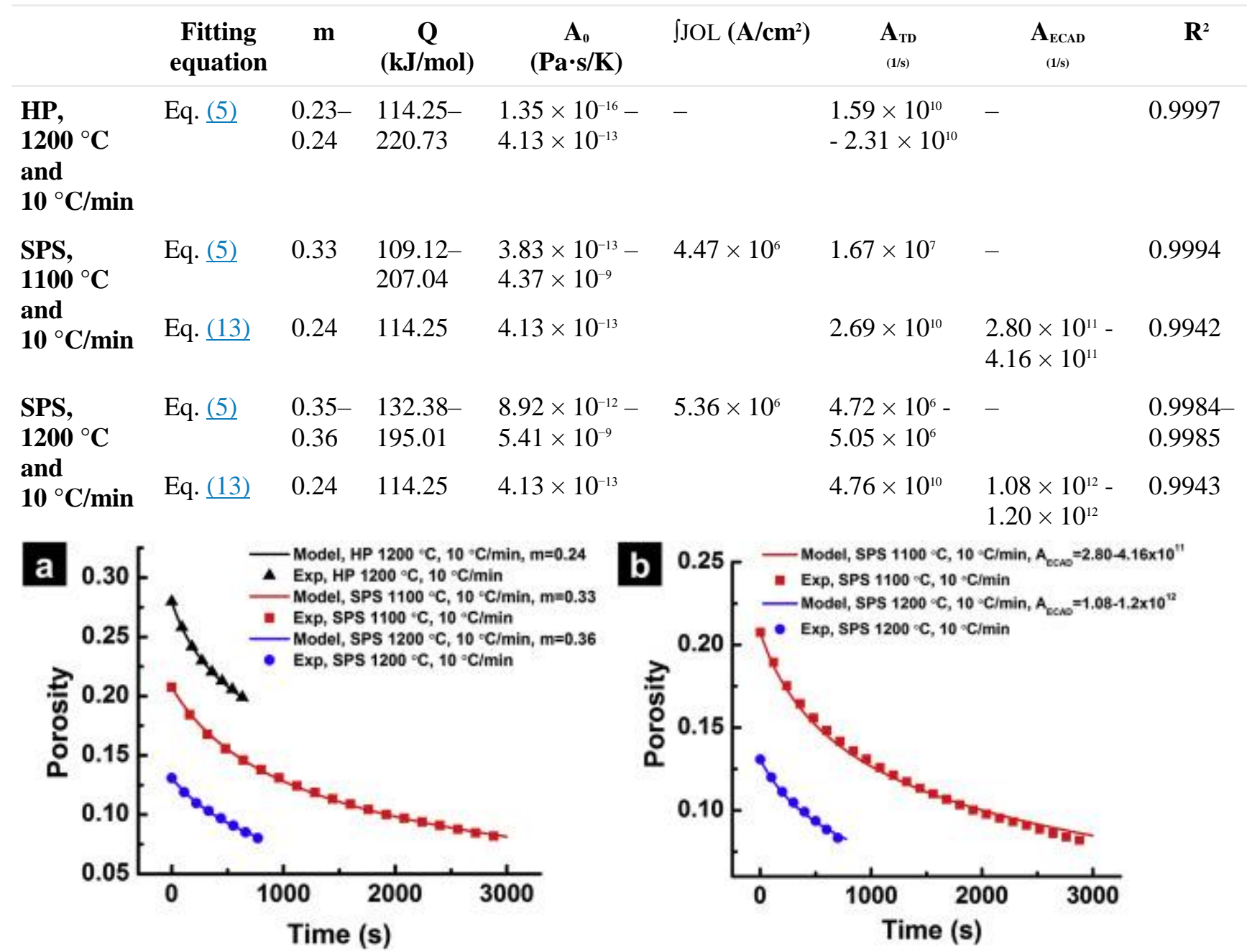

Fig. 6. (a) Experimental porosity evolution curves of ZrN specimens processed by HP or SPS fitted by Eq. (5), (A.1), (A.10), (A.2), (A.3), (A.4), (A.5), (A.6), (A.7), (A.8), (A.9) experimental porosity evolution curves of ZrN specimens processed by SPS fitted by Eq. (13) (Black triangle: HP with $1200^{\circ} \mathrm{C}$ and $10^{\circ} \mathrm{C} / \mathrm{min}$, red square: SPS with $1200^{\circ} \mathrm{C}$ and $10^{\circ} \mathrm{C} / \mathrm{min}$, and blue circle: SPS with $1200^{\circ} \mathrm{C}$ and $10^{\circ} \mathrm{C} / \mathrm{min}$ ). Applied compaction pressure was a $60 \mathrm{MPa}$. Detailed fitting parameters are shown in Table 3. (For interpretation of the references to colour in this figure legend, the reader is referred to the web version of this article.)

HP results showed $m=0.23-0.24$ and $Q=114.25-220.73 \mathrm{~kJ} / \mathrm{mol}$, and $S P S$ rendered $\mathrm{m}=0.33-0.36$ and $Q$ $=109.2-207.04 \mathrm{~kJ} / \mathrm{mol}$ (Table 3). The obtained $\mathrm{m}$ and $\mathrm{Q}$ in the HP study indicate that ZrN consolidation using HP is based on the dislocation climb controlled creep mechanism which agrees with results from Petrykina and Shvedova [64]. In contrast, $m$ and $Q$ values for SPS show that the densification mechanism is close to the glide controlled creep $(m=0.33)$. Creep deformation of $\mathrm{ZrN}$ during HP is controlled by the climb of dislocations over physical obstacles in the glide/climb sequential mechanism [46]. The electric current effect such as localized heating at defects and defects generation may facilitate the diffusion of the number of barriers encountered by a mobile dislocation, which assists the removal of the obstacle 
[65]. Also, a mobile dislocation that obtains energy from local Joule heating or an elastic field effect from vacancies generated by an electric current, can overcome obstacles more easily. The bulk vacancy concentration is important for the climb controlled creep [66]. Vacancy formation by local Joule heating can promote the dislocation climb. As a result, the overall rate limiting step of ZrN powder deformation during SPS can be transferred from the climb controlled to the dislocation glide controlled mechanism.

Alternatively, some previous studies showed that the densification mechanism is not changed by the electric current effect, as explained in section 3.3.1 [15], [16], [17], [11], [12], [13]. Therefore, we assume that the creep parameters ( $\mathrm{A} 0, \mathrm{~m}$ and $\mathrm{Q}$ ) are the same for both HP and SPS, and verify whether the electric current term in Eq. (13) can fit the experimentally observed porosity evolution corresponding to the SPS results.

Fig. 6(b) represents the best fitting results of the constitutive Eq. (13) taking into account the electric current effect based on the SPS experimental results and using the same values of $m, Q$ and $A 0$ as those found for HP. We use OLECD (section 3.2.2), the temperature dependent $\lambda$ and G of ZrN for the fitting. We found the best values of $\omega$ and $\beta$ rendering a good agreement with the porosity evolution experimentally determined during SPS.

One can see from Table 3 that, due to the similar ZrN temperature for $\mathrm{HP}\left(1200^{\circ} \mathrm{C}\right)$ and SPS $\left(1100{ }^{\circ} \mathrm{C}\right)$, parameter ATD is in the same range for both HP and SPS. That is why it is parameter AECAD, related to the electric current effect, which accelerates the densification during SPS compared with HP case. In SPS, higher temperature is obtained by applying higher electric current to the sample and the graphite die, which causes higher values of parameters , ATD and AECAD corresponding to SPS $\left(1200^{\circ} \mathrm{C}\right)$ case compared to SPS $\left(1100^{\circ} \mathrm{C}\right)$ case.

Due to the narrow density range during the holding stage under $92 \%$ relative density, we cannot evaluate the densification mechanism of $\mathrm{ZrN}$ for the fast heating rate SPS $\left(1200^{\circ} \mathrm{C}\right.$ and $\left.100{ }^{\circ} \mathrm{C} / \mathrm{min}\right)$ case. However, the smaller value for the fast heating rate SPS $\left(100^{\circ} \mathrm{C} / \mathrm{min}\right)$ compared to that of the slow heating rate SPS $\left(10^{\circ} \mathrm{C} / \mathrm{min}\right)$, as shown in Fig. 4, may indicate that the densification mechanism of $\mathrm{ZrN}$ is not changed.

In summary, the conducted experiments point out that the electric current affects the densification behavior of ZrN powder, which can be related to the current influence on the dislocation motion (electroplasticity phenomena). From the constitutive equations' fitting results, two conclusions can be derived. The accelerated dislocation mobility by electric current can change the densification mechanism (Fig. 6(a)). In contrast, the dislocation motion mechanism for $\mathrm{ZrN}$ is not changed (dislocation climb controlled creep), but the electric current can affect other parameters to assist the dislocation motion during SPS (Fig. 6(b)).

\section{Conclusions}

The effect of the electric current on spark plasma sintering (SPS) of ZrN powder was examined. For a rigorous comparison of SPS with hot pressing (HP), the processing parameters such as the actual 
temperature inside the powder, the electric current, and electric current density were measured or calculated. The electro-thermo-mechanical finite element modeling (FEM) of SPS showed that the vertical electrical and thermal contact resistances are crucial factors for obtaining the realistic values of the electric current flowing through the powder during SPS. The inter-particle neck area at the initial stage of sintering is small; therefore high electric current density can be developed and then reduced when the relative density is increased. Fitting the developed constitutive equation to the experimental porosity evolution observed in HP and SPS, showed that the densification mechanism of ZrN can be changed from dislocation climb to dislocation glide by the introduction of the electric current. For the first time, a constitutive equation of SPS taking into account the effect of the electric current effect was developed taking into consideration the enhanced dislocations motion by local resistive heating. The derived equation shows the possibility of the facilitation of the dislocation movement by an intrinsic current effect other than a change of the densification mechanism. The developed constitutive equation for SPS can be applied to obtain densification mechanisms for other electrically conductive materials subjected to field assisted sintering.

\section{Acknowledgement}

The support of the U.S. Department of Energy, Materials Sciences Division, under Award No. DESC0008581 is gratefully acknowledged.

REF

[1] K.R. Anderson, J.R. Groza, M. Fendorf, C.J. Echer, Surface oxide debonding in field assisted powder sintering, Mat. Sci. Eng. A 270 (2) (1999) $278 \mathrm{e} 282$.

[2] J.R. Groza, A. Zavaliangos, Sintering activation by external electrical field, Mat.

Sci. Eng. A 287 (2) (2000) 171e177.

[3] R. Chaim, Densification mechanisms in spark plasma sintering of nanocrystalline ceramics, Mat. Sci. Eng. A 443 (1e2) (2007) 25e32.

[4] J.M. Frei, U. Anselmi-Tamburini, Z.A. Munir, Current effects on neck growth in the sintering of copper spheres to copper plates by the pulsed electric current method, J. Appl. Phys. 101 (11) (2007) 114914e114918.

[5] N. Toyofuku, T. Kuramoto, T. Imai, M. Ohyanagi, Z.A. Munir, Effect of pulsed DC current on neck growth between tungsten wires and tungsten plates during the initial stage of sintering by the spark plasma sintering method, J. Mater. 
Sci. 47 (5) (2012) 2201e2205.

[6] Z. Trzaska, J.-P. Monchoux, Electromigration experiments by spark plasma sintering in the silverezinc system, J. Alloys Compd. 635 (0) (2015) 142e149.

[7] E.S. Machlin, Applied voltage and the plastic properties of "Brittle' rock salt, J. Appl. Phys. 30 (7) (1959) 1109e1110.

[8] H. Conrad, Electroplasticity in metals and ceramics, Mat. Sci. Eng. A 287 (2) (2000) $276 e 287$.

[9] J. Narayan, A new mechanism for field-assisted processing and flash sintering of materials, Scr. Mater 69 (2) (2013) 107e111.

[10] H. Conrad, Thermally activated plastic flow of metals and ceramics with an electric field or current, Mat. Sci. Eng. A 322 (1e2) (2002) $100 \mathrm{e} 107$.

[11] D. Yang, H. Conrad, Plastic deformation of fine-grained $\mathrm{Al} 2 \mathrm{O} 3$ in the presence of an electric field, Scr. Mater 41 (4) (1999) 397e401.

[12] J. Campbell, Y. Fahmy, H. Conrad, Influence of an electric field on the plastic deformation of fine-grained Al2O3, Metall Mat Trans A 30 (11) (1999) 2817 e2823.

[13] H. Conrad, D. Yang, Influence of an electric field on the plastic deformation of fine-grained $\mathrm{MgO}$ at high homologous temperatures, Acta Mater 48 (16) (2000) 4045e4052.

[14] H.J. Frost, M.F. Ashby, Deformation-mechanism Maps, the Plasticity and Creep of Metals and Ceramics, Pergamon Press, Oxford, 1982.

[15] J. Langer, M.J. Hoffmann, O. Guillon, Electric field-assisted sintering and hot

[16] J. Langer, M.J. Hoffmann, O. Guillon, Electric field-assisted sintering in comparison with the hot pressing of yttria-stabilized zirconia, J. Am. Ceram. Soc.

94 (1) (2011) $24 \mathrm{e} 31$. 
[17] J. Langer, M.J. Hoffmann, O. Guillon, Direct comparison between hot pressing and electric field-assisted sintering of submicron alumina, Acta Mater 57 (18) (2009) 5454e5465.

[18] H. Su, D.L. Johnson, Master sintering curve: a practical approach to sintering, J. Am. Ceram. Soc. 79 (12) (1996) 3211 e3217.

[19] M. Demuynck, J.-P. Erauw, O. Van der Biest, F. Delannay, F. Cambier, Densification of alumina by SPS and HP: a comparative study, J. Eur. Ceram. Soc. 32

(9) (2012) 1957e1964.

[20] G. Bernard-Granger, C. Guizard, Spark plasma sintering of a commercially available granulated zirconia powder: I. Sintering path and hypotheses about the mechanism(s) controlling densification, Acta Mater 55 (10) (2007) $3493 e 3504$.

[21] W. Li, E.A. Olevsky, J. McKittrick, A.L. Maximenko, R.M. German, Densification mechanisms of spark plasma sintering: multi-step pressure dilatometry, J. Mater. Sci. 47 (20) (2012) 7036e7046.

[22] E.V. Aleksandrova, A.M. Ilyina, E.G. Grigoryev, E.A. Olevsky, Contribution of electric current into densification kinetics during spark plasma sintering of conductive powder, J. Am. Ceram. Soc. 98 (11) (2015) 3509e3517.

[23] A. Zavaliangos, J. Zhang, M. Krammer, J.R. Groza, Temperature evolution during field activated sintering, Mat. Sci. Eng. A 379 (1e2) (2004) 218e228.

[24] C. Maniere, A. Pavia, L. Durand, G. Chevallier, K. Afanga, C. Estourn es, Finiteelement modeling of the electro-thermal contacts in the spark plasma sintering process, J. Eur. Ceram. Soc. 36 (3) (2016) 741e748.

[25] C. Maniere, G. Lee, E.A. Olevsky, Proportional integral derivative, modeling and ways of stabilization for the spark plasma sintering process, Results Phys. 7 (2017) 1494e1497. 
[26] G. Lee, M.S. Yurlova, D. Giuntini, E.G. Grigoryev, O.L. Khasanov, J. McKittrick, E.A. Olevsky, Densification of zirconium nitride by spark plasma sintering and high voltage electric discharge consolidation: a comparative analysis, Ceram. Int. 41 (10, Part B) (2015) 14973e14987.

[27] J. Adachi, K. Kurosaki, M. Uno, S. Yamanaka, Effect of porosity on thermal and electrical properties of polycrystalline bulk ZrN prepared by spark plasma sintering, J. Alloys Compd. 432 (1e2) (2007) 7e10.

[28] W. Chen, J.Z. Jiang, Elastic properties and electronic structures of 4d- and 5 dtransition metal mononitrides, J. Alloys Compd. 499 (2) (2010) 243e254.

[29] C. Maniere, U. Kus, L. Durand, R. Mainguy, J. Huez, D. Delagnes, C. Estourn es, Identification of the norton-green compaction model for the prediction of the Tie6Ale4V densification during the spark plasma sintering process, Adv. Eng. Mater 18 (10) (2016) 1720e1727.

[30] C. Maniere, L. Durand, E. Brisson, H. Desplats, P. Carr e, P. Rogeon, C. Estourn es, Contact resistances in spark plasma sintering: from in-situ and ex-situ determinations to an extended model for the scale up of the process, J. Eur.

Ceram. Soc. 37 (4) (2016) 1593e1605.

[31] V. Basini, J.P. Ottaviani, J.C. Richaud, M. Streit, F. Ingold, Experimental assessment of thermophysical properties of $(\mathrm{Pu}, \mathrm{Zr}) \mathrm{N}, \mathrm{J}$. Nucl. Mater 344 (1e3) (2005) $186 \mathrm{e} 190$.

[32] K.I. Rybakov, E.A. Olevsky, V.E. Semenov, The microwave ponderomotive effect on ceramic sintering, Scr. Mater 66 (12) (2012) 1049e1052.

[33] R. Orrù, R. Licheri, A.M. Locci, A. Cincotti, G. Cao, Consolidation/synthesis of materials by electric current activated/assisted sintering, Mater. Sci. Eng. $R$ Rep. 63 (4e6) (2009) 127e287.

[34] X. Wei, D. Giuntini, A.L. Maximenko, C.D. Haines, E.A. Olevsky, Experimental investigation of electric contact resistance in spark plasma sintering tooling 
setup, J. Am. Ceram. Soc. 98 (11) (2015) 3553e3560.

[35] M. Yoneya, T. Ikeshoji, A numerical calculation method advantageous for complex boundary problems -an application to the pulse discharge sintering process, Mater. Trans. 42 (11) (2001) 2165e2171.

[36] N. Chawake, L.D. Pinto, A.K. Srivastav, K. Akkiraju, B.S. Murty, R.S. Kottada, On Joule heating during spark plasma sintering of metal powders, Scr. Mater 93 (2014) 52e55.

[37] H.F. Fischmeister, E. Arzt, Densification of powders by particle deformation, Powder Metall. 26 (2) (1983) 82e88.

[38] A.S. Helle, K.E. Easterling, M.F. Ashby, Hot-isostatic pressing diagrams: new developments, Acta Metall. 33 (12) (1985) 2163e2174.

[39] A.F. Sprecher, S.L. Mannan, H. Conrad, Overview no. 49: on the mechanisms for the electroplastic effect in metals, Acta Metall. 34 (7) (1986) 1145e1162.

[40] H. Conrad, A.F. Sprecher, W.D. Cao, X.P. Lu, Electroplasticitydthe effect of electricity on the mechanical properties of metals, JOM 42 (9) (1990) 28e33. [41] W.A. Salandro, J.J. Jones, C. Bunget, L. Mears, J.T. Roth, The Effect of Electric Current on Metals, Electrically Assisted Forming: Modeling and Control,

[42] B. Ruszkiewicz, T. Grimm, I. Ragai, L. Mears, J.T. Roth, A review of electricallyassisted manufacturing with emphasis on modeling and understanding of the electroplastic effect, J. Manuf. Sci. Eng. 139 (11) (2017), https://doi.org/ 10.1115/1.4036716, 110801. (15 pages), Paper No: MANU-17-1033.

[43] M. Gendre, A. Maître, G. Trolliard, A study of the densification mechanisms during spark plasma sintering of zirconium (oxy-)carbide powders, Acta Mater 58 (7) (2010) 2598e2609.

[44] W. Ji, S.S. Rehman, W. Wang, H. Wang, Y. Wang, J. Zhang, F. Zhang, Z. Fu, Sintering boron carbide ceramics without grain growth by plastic deformation 
as the dominant densification mechanism, Sci. Rep. 5 (2015) 15827.

[45] Z. Trzaska, A. Couret, J.-P. Monchoux, Spark plasma sintering mechanisms at the necks between TiAl powder particles, Acta Mater 118 (2016) 100e108.

[46] T.G. Nieh, J. Wadsworth, O.D. Sherby, Superplasticity in Metals and Ceramics, Cambridge University Press, Cambridge, 1997.

[47] J.T. Roth, I. Loker, D. Mauck, M. Warner, S.F. Golovashchenko, A. Krause, Enhanced formability of 5754 aluminum sheet metal using electric pulsing,

Trans. North Am. Manuf. Res. Inst. SME 36 (2008) 405e412.

[48] T. Ung

ar, A. Borbely, The effect of dislocation contrast on x-ray line broad-

ening: a new approach to line profile analysis, Appl. Phys. Lett. 69 (21) (1996) $3173 \mathrm{e} 3175$.

[49] T. Ungar, I. Dragomir, A. Revesz, A. Borbely, The contrast factors of dislocations in cubic crystals: the dislocation model of strain anisotropy in practice, J. Appl.

Crystallogr. 32 (5) (1999) 992e1002.

[50] S. Deng, R. Li, T. Yuan, S. Xie, M. Zhang, K. Zhou, P. Cao, Direct currentenhanced densification kinetics during spark plasma sintering of tungsten

powder, Scr. Mater 143 (2018) 25e29.

[51] K. Okazaki, M. Kagawa, H. Conrad, A study of the electroplastic effect in metals, Scr. Metall. 12 (11) (1978) 1063e1068.

[52] W. Kang, I. Beniam, S.M. Qidwai, In situ electron microscopy studies of electromechanical behavior in metals at the nanoscale using a novel microdevicebased system, Rev. Sci. Instrum. 87 (9) (2016) 095001.

[53] S.-J. Kim, S.-D. Kim, D. Yoo, J. Lee, Y. Rhyim, D. Kim, Evaluation of the athermal effect of electric pulsing on the recovery behavior of magnesium alloy, Metall Mat Trans A 47 (12) (2016) 6368e6373.

[54] E.A. Olevsky, Theory of sintering: from discrete to continuum, Mat. Sci. Eng. R. 
23 (2) (1998) 41e100.

[55] G. Lee, J. McKittrick, E. Ivanov, E.A. Olevsky, Densification mechanism and mechanical properties of tungsten powder consolidated by spark plasma sintering, Int. J. Refract. Met. Hard Mater 61 (2016) 22e29.

[56] R.K. Bordia, S.-J.L. Kang, E.A. Olevsky, Current understanding and future research directions at the onset of the next century of sintering science and technology, J. Am. Ceram. Soc. 100 (6) (2017) 2314e2352.

[57] V.O. Zlokazov, V.V. Potemkin, A.V. Stepanov, D.G. Chikin, Influence of structural defects on $1 / \mathrm{f}$ in thin niobium films, Radiophys. Quantum Electron. 35

(11) (1992) 610e613.

[58] M. Kumar, N. Umezawa, S. Ishii, T. Nagao, Examining the performance of refractory conductive ceramics as plasmonic materials: a theoretical approach,

ACS Photonics 3 (1) (2016) 43e50.

[59] J.E. Garay, S.C. Glade, U. Anselmi-Tamburini, P. Asoka-Kumar, Z.A. Munir, Electric current enhanced defect mobility in Ni3Ti intermetallics, Appl. Phys. Lett. 85 (4) (2004) 573e575.

[60] R. Raj, M. Cologna, J.S.C. Francis, D.J. Green, Influence of externally imposed and internally generated electrical fields on grain growth, diffusional creep, sintering and related phenomena in ceramics, J. Am. Ceram. Soc. 94 (7) (2011) $1941 \mathrm{e} 1965$.

[61] S.K. Jha, R. Raj, The effect of electric field on sintering and electrical conductivity of titania, J. Am. Ceram. Soc. 97 (2) (2014) 527e534.

[62] T. Kino, T. Endo, S. Kawata, Deviations from Matthiessen's rule of the electrical resistivity of dislocations in aluminum, J. Phys. Soc. Jpn. 36 (3) (1974) $698 \mathrm{e} 705$.

[63] D. Hull, D.J. Bacon, Chapter 10-Strength of Crystalline Solids, Introduction to Dislocations, fifth ed., Butterworth-Heinemann, Oxford, 2011, pp. 205e249. 
[64] R.Y. Petrykina, L.K. Shvedova, Hot pressing of transition metal nitrides and their properties, Sov. Powder Metall. 11 (4) (1972) $276 e 279$.

[65] W. Cao, A.F. Sprecher, H. Conrad, Measurement of the electroplastic effect in Nb, J. Phys. E. Sci. Instrum. 22 (12) (1989) 1026e1034.

[66] P.-A. Geslin, B. Appolaire, A. Finel, Multiscale theory of dislocation climb, Phys.

Rev. Lett. 115 (26) (2015) 265501.

[67] R.G. Sheppard, D. Morgan, D.M. Mathes, D.J. Bray, Properties and Characteristics of Graphite, Poco Graphite, Inc, 1987.

[68] S. Munoz, U. Anselmi-Tamburini, Temperature and stress fields evolution during spark plasma sintering processes, J. Mater. Sci. 45 (23) (2010) $6528 \mathrm{e} 6539$. 